\title{
POLÍTICAS DE PROMOÇÃO DA IGUALDADE RACIAL IMPULSO ÀS ACCÕES AFIRMATIVAS E À EDUCAÇÃO ÉTNICO-RACIAL
}

\author{
POLICIES FOR THE PROMOTION OF RACIAL EQUALITY: IMPULSE TO AFFIRMATIVE \\ ACTIONS AND ETHNI-RACIAL EDUCATION
}

POLÍTICAS DE PROMOCIÓN DE LA IGUALDAD RACIAL: IMPULSO A LAS ACCIONES AFIRMATIVAS Y A LA EDUCACIÓN ÉTNICO-RACIAL

Matilde Ribeiro*

Doutora em Serviço Social pela Pontifícia Universidade Católica de São Paulo (PUC/SP) Professora na área de humanidades na Universidade de Integração Internacional da Lusofonia Afro-brasileira (UNILAB). E-mail: matilderibeiro@uol.com.br

REVISTA PEDAGÓGICA

Revista do Programa de Pós-graduação em Educação da Unochapecó | ISSN 1984-1566 Universidade Comunitária da Região de Chapecó | Chapecó-SC, Brasil Como referenciar este artigo: RIBEIRO, M. Políticas de promoção da igualdade racial: impulso às ações afirmativas e à educação étnico-racial. Revista Pedagógica, Chapecó, v.16, n.33, p. 109-126, Jul./Dez. 2014.

\begin{abstract}
RESUMO: O artigo - Políticas de promoção da igualdade racial: impulso às ações afirmativas e a educação étnico-racial, é um recorte da tese de doutorado concluída em 2013. O objetivo do artigo é destacar informações e reflexões sobre a educação étnico-racial como importante ferramenta para construção de direitos, justiça e democracia, visando contribuir para a alteração do quadro histórico de profundas desigualdades sociais e raciais em nosso país. $\mathrm{O}$ artigo é estruturado por dois itens: Caminhos de construção das políticas de promoção da igualdade racial e Ações Afirmativas e educação étnico-racial. Destaca-se a relevância do tema para reflexões e debates sobre a atualidade de processos sociais e educacionais, para os setores acadêmicos e sociais, e, demais interessados.
\end{abstract}

PALAVRAS-CHAVE: Politicas de igualdade racial. Ações afirmativas. Educação étnicoRacial.

\begin{abstract}
The paper entitled "Politics of promotion of race equality: an impulse to affirmative actions and ethnic-racial education" results from the author's doctoral dissertation concluded in 2013. Hence, it presents a briefing which focuses on highlighting information and reflections on ethnic-racial education as an important tool for the establishment of rights, justice and democracy. This discussion aims at contributing for a change in the historical configuration of deep social and racial inequalities in our country. In order to present the subject at hand, this paper is divided in two larger themes: roads for the construction of politics of promotion of racial equality; and affirmative actions and ethnic-racial education. The relevance of the topic is related to reflections and debates circa current social and educational processes both in academic and social environments.
\end{abstract}

KEYWORDS: Racial equality politics. Affirmative actions. Ethnic-racial education. 
*Ministra da Secretaria de Promoção da Igualdade Racial do Governo Federal (2003/2008). Integra o Conselho Nacional dos Direitos da Mulher (CNDM); o Conselho África do Instituto Lula; o Conselho Nacional de Formação Política da Fundação Perseu Abramo, e, o Conselho Consultivo da Revista Estudos Feministas. Foi Secretária Adjunta na Secretaria de Promoção de Políticas de Igualdade Racial da Prefeitura de São Paulo (2013-2014).
1 Militante do Movimento Negro, Abdias do Nascimento Nasceu em Franca/SP em 14/03/1914 e faleceu no Rio de Janeiro em 24/05/2011. Além da militância, como parlamentar, gestor, artista e intelectual consagrou-se pela defesa intransigente do respeito à dignidade humana. Como deputado federal (1983-1987) e senador (1991-1999) foi incisivo, apresentando projetos de lei que contribuíram para definir caminhos para o combate ao racismo.

\section{CAMINHOS DE CONSTRUÇÃO DAS POLÍTICAS DE PROMOÇÃO DA IGUALDADE RACIAL}

As reflexões teóricas e políticas e demandas por investimento público inclusivo do ponto de vista étnicoracial vêm de longas datas, desde a colonização, ou melhor, desde a invasão europeia com a exploração dos recursos naturais e o estabelecimento do trabalho escravizado primeiro dos indígenas e depois dos africanos. Para Mário Maestri (1994) e Jacob Gorender (2010), a referência ao processo de chegada dos europeus em terras brasileiras é definida como invasão (e não como descobrimento), a considerar que aqui já viviam os indígenas.

Em contestação a essa realidade, Abdias do Nascimento ${ }^{1}$ utilizava comumente em suas palestras e discursos uma emblemática frase: "A luta pela liberdade inicia-se desde o momento que a/o primeira/o negra/o foi escravizada/o no Brasil, após ter sido capturada/o na África”. Esta lembrança, sem dúvida, conecta-se com o importante arsenal teórico por ele deixado, no que diz respeito à análise sobre escravização e à realidade da população negra (Nascimento, 2003, 1982, 1980).

Mulheres e homens negros escravizados construíram parte importante da vida nacional, porém, não são reconhecidos em sua humanidade. Segundo Gorender (2010), houve por parte do escravismo o posicionamento de 'coisificar' os escravizados, e, de certa forma, essa postura continuou depois da abolição.

Faz-se importante destacar a condição vivida pelas mulheres negras escravizadas, que como parte da luta geral contra o regime da escravidão, enfrentavam em particular os aspectos patriarcais e sexistas, a considerar o necessário e cotidiano repúdio à exploração sexual.

Nesse sentido, Marcelo Paixão (2006, p. 31) alega que o escravismo foi especialmente cruel com as mulheres,

Gilberto Freyre, em Casa-grande \& Senzala,
já admitira que não havia escravidão sem
depravação sexual. As mulheres negras
durante séculos foram vítimas de múltiplas
formas de exploraçãa que incidiram no
plano da produção e da reprodução da
vida doméstica e por meio de estupros
cotidianamente cometidos nas casas-grandes
e nas senzalas. (Paixão, 2006, p.31).

Buscandoreverter a situaçãode 'coisificação'mulheres e homens negros foram e continuam sendo persistentes na reação ao inaceitável regime de escravização e à condição de não cidadania (na atualidade). Os processos de luta foram 
demarcados de várias maneiras, por revolta coletiva e/ou por manifestações individuais cotidianas, como respostas aos tratamentos discriminatórios e racistas.

A escravização, a abolição e a forma como foi constituída a ideia de nação brasileira caracterizam a doutrina da supremacia racial e do racismo. E, ainda, o racismo vincula-se a outros elementos que se configuram como mecanismos de desigualdades, tais como o preconceito, o estereótipo e a discriminação. Para Kabengele Munanga e Nilma Lino Gomes (2004, p. 179), o racismo é um comportamento, uma ação resultante da aversão,

por vezes, do ódio, em relação a pessoas que possuem um pertencimento racial observável por meio de sinais, tais como a cor da pele, tipo de cabelo, formato do olho etc. Ele é resultado da crença de que existem raças ou tipos humanos superiores e inferiores, a qual se tenta impor como única e verdadeira. Exemplo disso são as teorias raciais que serviram para justificar a escravidão no século XIX, a exclusão de negros e a discriminação racial. (Munanga; Gomes, 2004, p.179)

Ainda, referindo-se à América Latina e Caribe, onde houve escravidão, Hélio Santos (2001, p. 33) considera que o racismo é

\begin{abstract}
dissimulado e por isso perverso, pois apresenta ser mais brando, exatamente como ocorre no Brasil. Assim se dá com os negros no Uruguai, Venezuela, Peru,Colômbia e Cuba. Há aqui, por parte das elites, um entendimento generalizado, mas que raramente tem coragem de vir a público. Trata-se de entender que o país seria melhor caso nossos estoques raciais fossem também 'melhores'. Melhor aqui significa ter uma população em que a presença de negros, mestiços e índios fosse menor. (Santos, 2001, p.33)
\end{abstract}

2 A pesquisa do Datafolha (Racismo Cordial, 1995) reafirmou, na opinião pública, a imagem do Brasil como um país onde vigora a democracia racial, com base em uma relação pacífica entre as raças. A pesquisa apontou a vigência de um 'racismo cordial', visão fortemente criticada por muitos estudiosos das relações raciais, segundo os quais a pesquisa tende a reforçar preconceitos raciais.
A considerar as formulações de Munanga e Gomes (2004) e de Santos (2001), a forma aversiva que é o racismo pressupõe a existência de um sistema social e político dotado de mecanismos que produzem desigualdades sociais e raciais, que, a depender da abordagem histórica e/ou teórica, apresenta-se como mais ou menos intensa.

Esse sistema tão bem engendrado, tendo por base o racismo, vem se estruturando e modificando ao longo dos séculos, mantendo sua centralidade que é a dominação e a exploração, permanecendo como um fenômeno arraigado na sociedade.

Segundo João José Reis (200o, p. 96), mesmo que o racismo brasileiro tenha sido chamado de cordial $^{2}$ o 
3 Lélia Gonzalez despontou-se como importante ativista negra no período contemporâneo. Nasceu em Belo Horizonte, mas viveu e atuou politicamente no Rio de Janeiro, onde faleceu em 1994. Atuou como professora universitária na área de História e Geografia, e, entre 1978 e 1982 esteve à frente da Comissão Executiva Nacional do Movimento Negro Unificado(MNU). Teve inserção junto a vários setores do movimento social, destacando-se a luta contra o racismo e o machismo. resultado é perverso, os negros permanecem 'em seu lugar', não têm representação em espaços políticos e de poder. Portanto, o racismo não é produto do desvio de alguns racistas, é parte do sistema que tem por base a exploração e a desumanização dos seres humanos, gerando profundas exclusões.

Constata-se que a exclusão da população negra faz parte da doutrina de supremacia racial, incorpora desigualdades como parte de mecanismos discriminatórios que se expressam além dos indivíduos, o que caracteriza o racismo institucional (também chamado de estrutural ou sistêmico), que é definido como fracasso coletivo das organizações e das instituições, pelo fato de não atender às necessidades das pessoas por causa da sua cor, cultura, origem racial ou étnica. Assim, os resultados diretos do racismo institucional são o acesso desigual a oportunidades, aos bens e serviços públicos e privados, e a garantia de vida com qualidade. Com isso, os negros e os indígenas, e, entre esses, as mulheres, são os mais pobres entre os pobres.

A existência da pobreza histórica define que lugar o ser humano ocupa na estrutura social. Assim, Lélia Gonzalez $^{3}$ (1982, p. 15), no livro Lugar de Negro traz importantes contribuições para a reflexão sobre os espaços destinados à população negra:

O lugar natural do grupo branco dominante são moradias amplas, espaçosas, situadas nos mais belos recantos da cidade ou do campo e devidamente protegidas por diferentes tipos de policiamento: desde os antigos feitores, capitães do mato, capangas etc., até a polícia formalmente constituída. Desde a casa-grande e do sobrado, aos belos edifícios e residências atuais, o critério tem sido sempre o mesmo. Já o lugar natural do negro é o oposto, evidentemente: da senzala às favelas, cortiços, porões, invasões, alagados e conjuntos 'habitacionais' (cujos modelos são guetos dos países desenvolvidos) dos dias de hoje, o critério também tem sido simetricamente o mesmo: a divisão racial do espaço. (Gonzalez, 1982, p.15).

As posições críticas quanto à divisão racial do espaço, fazem parte da denúncia do mito da democracia racial.Segundo Octavio Ianni (2004, p. 333), com a constituição da sociedade de classes, a partir da crise das formas econômicas e sociais escravocratas, verificou-se a reconstrução do auto representação da nova ordem social: "[...] em consequência, o mito da democracia racial surge como uma expressão particular do mito mais amplo da sociedade aberta, em que os homens pobres ou ricos, de qualquer raça, sexo ou religião - são definidos ideologicamente como iguais". 
$4 \mathrm{O}$ autor apresenta reflexões a partir de quatro períodos: a primeira fase do Movimento Negro organizado na República (1888-1937): da Primeira República ao Estado Novo; a segunda fase do Movimento Negro organizado na República (19451964): da Segunda República à ditadura militar; a terceira fase do Movimento Negro organizado na República (1978-200o): do início do processo de redemocratização à República Nova; e, quarta fase do Movimento Negro da República (2000 - ?): uma hipótese interpretativa.
O Movimento Negro brasileiro, de maneira afirmativa e na contramão da lógica de subjugação da população negra, construiu demandas materiais e objetivas que, segundo Antônio Sergio Alfredo Guimarães (2002, p. 91), apresentam-se como objetivo de reeducar a sociedade e integrar socialmente os negros.

Portanto, focando na importância da participação social e garantia de direito e justiça sociorracial, o Movimento Negro imbrica-se ao processo histórico do país. Nesse contexto, Petrônio Domingues (2007, p. 101) analisou essa organização durante a República (1889$2000)^{4}$ e definiu como luta dos negros a perspectiva de resolver problemas em nossa sociedade,

em particular os provenientes dos preconceitos e das discriminações raciais, que os marginalizam no mercado de trabalho, no sistema educacional, político, social e cultural. Para o movimento negro, a 'raça', e, por conseguinte, a identidade racial, é utilizada não só como elemento de mobilização, mas também de mediação das reivindicações políticas. (Domingues, 2007, p.101).

Assim, diante do papel político do Movimento Negro a 'raça' determina a atuação em torno de um projeto comum de transformação social. As formulações de Domingues (2007) aproximam-se das reflexões de Guimarães (2002, p. 101), no que se refere a estratégias de intervenção, como todo movimento político, em representação a população negra e do conjunto que contesta o racismo (inclusive os brancos e asiáticos) e em diálogo com toda a sociedade "o movimento negro se nutre de tradições e de elos com movimentos contemporâneos, internos e externos ao país, retirando daí sua atualidade e eficácia ideológica. Foi o que fizeram as principais lideranças intelectuais e políticas, como Abdias do Nascimento e Lélia Gonzalez".

Nos estudos sobre os movimentos sociais, é fundamental considerar as reflexões a partir das críticas às posturas economicistas, que ao longo da história não levaram em consideração as especificidades das organizações - como as questões raciais, étnicas, de gênero, de geração, as ambientais, entre outras - em detrimento da luta de classes.

Sandra Azeredo (1994) adverte sobre a necessidade de busca da compreensão de que raça, assim como gênero, constitui-se em relações de poder e, portanto, determina tanto a vida de mulheres e homens brancos como a de mulheres e homens negros. Sendo assim, impõe-se que as questões raciais e étnicas sejam consideradas como parte da estrutura social, não devendo ser vistas apenas como responsabilidade das mulheres negras (ao que se pode 
5 Como exemplos, encontram-se referências sobre o tema em estudos internacionais e nacionais. Em âmbito internacional: Kia Lilly Caldwell (2007); Kimberlé Crenshaw (2002); Sonia Alvarez (2009). E no Brasil: Cida Bento (1995); Fatima Oliveira, Nilza Iraci e Matilde Ribeiro (1995 e 2006); Luiza Bairros (1995); Sandra Azeredo (1994); Sueli Carneiro (2003), e Vera Soares (2004).

6 “Em 1988 as mulheres negras dão impulso para a construção de sua organização com fisionomia própria e caráter nacional, visando intensificar as reflexões e ações para o combate às opressões racial e de gênero. Este processo foi possível seja pelos aprendizados a partir da resistência de nossas ancestrais, seja pelos acúmulos das experiências anteriores daquelas mulheres negras e 'agrupamentos' que se embrenharam neste processo atual de organização" (RIBEIRO, 1995, p. 450). acrescentar que não é de responsabilidade também só dos negros, e sim de toda a sociedade).

Kimberlé Crenshaw (2002, p. 173) destaca a importância da interseccionalidade entre gênero e raça e da coexistência entre ambas. Para a autora, a incorporação de gênero "põe em destaque as formas pelas quais homens e mulheres são diferentemente afetados pela discriminação racial e por outras intolerâncias correlatas".

A partir da produção de estudiosas feministas ${ }^{5}$, mais diretamente, sobre a crítica à invisibilidade imposta às mulheres negras do ponto de vista da sociedade e dos movimentos negro e feminista, são apontadas suas potencialidades políticas e organizativas.

No que diz respeito à realidade brasileira, Sueli Carneiro (2003, p. 58) ressalta que nos últimos períodos, as mulheres negras brasileiras ${ }^{6}$

encontraram seu caminho de
autodeterminação política, soltaram suas
vozes, brigaram por espaço e representação
e se fizeram presentes em todos os
espaços de importância para o avanço da
questão da mulher brasileira hoje. Foi sua
temática a que mais cresceu politicamente
no movimento de mulheres do Brasil,
integrando, espera-se que definitivamente,
a questão racial no movimento de mulheres.
O que impulsiona essa luta é a crença 'na
possibilidade de construção de um modelo
civilizatório humano, fraterno e solidário,
tendo como base os valores expressos pela
luta antirracista, feminista e ecológica,
assumidos pelas mulheres negras de todos
os continentes, pertencentes que somos
à mesma comunidade de destinos'. Pela
construção de uma sociedade multirracial
e pluricultural, onde a diferença seja
vivida como equivalência e não mais como
inferioridade. (Carneiro, 20o3, p.58).

Carneiro(2003)valorizaoresultadodoenegrecimento do Movimento Feminista e da ampliação do protagonismo das mulheres negras no Movimento Negro (e movimento social de maneira geral) e na sociedade, como um aspecto altamente positivo.

As vozes teórico-políticas das últimas décadas, sem dúvida ecoam formulações dos que lutaram desde os primórdios. Ecoam, também, vozes dos períodos mais recentes contrariando a suposta democracia racial, como as de Roger Bastide e Florestan Fernandes (2008, p. 155) já em 1955 apontaram "a falta de uma política governamental a favor da ascensão do homem de cor na sociedade".

No entanto, as políticas de igualdade racial passam a existir de maneira mais acentuada apenas a partir dos 
anos 1980, tendo como impulso o tensionamento feito pelo Movimento Negro e organização de mulheres negras, e decisão de governos vinculados a partidos políticos e instituições democráticas.

Entre os vários momentos de protagonismo do Movimento Negro e das organizações de mulheres negras, destacam-se as mobilizações no período PréConstituinte (1986/88), a Marcha Zumbi dos Palmares Contra o Racismo, pela Cidadania e a Vida (MZP - 1995) e a Campanha Eleitoral do presidente Luiz Inácio Lula da Silva (com o Programa Brasil sem Racismo - PRB, 2002). Apesar de a lista de reivindicações históricas ser quilométrica, a partir da sistematização destes documentos, constatam-se como foco de agenda política12 temas - Terra, Educação, Condições de Vida e Saúde, Trabalho, Segurança/Violência Policial, Cultura e Comunicação, Relações Internacionais, Democratização da Informação, Religião, Juventude, Mulher e Menor (passando a ser denominado a partir dos anos 1980 - Criança e Adolescente).

Dessa maneira, o desenvolvimento das políticas de igualdade racial deu-se num primeiro momento a partir de experiências locais (Municípios e Estados), e posteriormente em âmbito Federal - com a criação da Fundação Cultural Palmares (em 1988), do Grupo de Trabalho Interministerial - GTI (em 1996) e da Secretaria Especial de Políticas de Promoção da Igualdade Racial SEPPIR (em 2003), sendo estas estruturas acompanhadas de várias iniciativas de normatização, leis e procedimentos, nas várias áreas da administração pública.

Nesse mesmo período, atividades simbólicas, como a consagração de Zumbi dos Palmares como Herói Nacional inscrito no Livro Dos Heróis Da Pátria e a oficialização da data de sua morte - 20 de Novembro como o Dia Nacional da Consciência Negra, também demarcaram sua importância.

Mais recentemente, no percurso do executivo sobre a institucionalização das políticas de igualdade racial, destacam-se: o Plano Plurianual - PPA (documento que abrange as diretrizes para o conjunto das políticas públicas); a Política e o Plano Nacional de Promoção da Igualdade Racial; o Fórum Intergovernamental de Promoção da Igualdade Racial - FIPIR; o Conselho Nacional e a Conferência Nacional de Igualdade Racial - CNPIR; e o Estatuto da Igualdade Racial.Destaca-se, ainda, a construção do Sistema Nacional de Promoção da Igualdade Racial (SINAPIR).

\section{AÇÕES AFIRMATIVAS E EDUCAÇÃO ÉTNICO- RACIAL}

Ao se refletir sobre o percurso de institucionalização das políticas de igualdade racial no Brasil, constata-se 
7 Um exemplo de ação coletiva dirigida à alteração na aplicação do censo foi a campanha: Não Deixe sua Cor Passar em Branco, responda com bom censo/senso, realizada no final dos anos 1990 a partir de uma forte aliança do Movimento Negro com diferentes instituições da sociedade civil, sob a coordenação do Instituto Brasileiro de Análises Sociais e Econômicas (IBASE).Essa campanha foi referenciada pelo Censo IBGE-200o, e os objetivos foram:sensibilizar pessoas de origem africana a declarar a sua cor a partir do seu referencial étnico; contribuir na construção de indicadores nacionais sobre as condições socioeconômicas da população de origem africana; e, fazer veicular uma mensagem positiva da população de origem negra tendo em vista a recuperação de sua autoestima cultural e política. o fortalecimento das ações afirmativas, como estratégia que tomou corpo, na última década, como expressão do acúmulo da luta do Movimento Negro e das organizações das mulheres negras em negociação com o Estado brasileiro, tendo em vista as necessidades da população negra.

Ressalta-se que o enfrentamento às discriminações históricas deve se dar a partir da consideração das possibilidades de mudanças visando à valorização da identidade negra, de pressões e negociações institucionais e de reflexões e ações concretas na sociedade, que contribuem para que novas visões e posturas democráticas passem a vigorar.

Nessa perspectiva, o conhecimento da realidade da população negra brasileira torna-se fundamental. Importante exemplo é o Censo 2010, realizado pelo Instituto Brasileiro de Geografia e Estatística (IBGE), onde se verifica aumento do percentual de negros, como uma progressão dos últimos anos7. A população brasileira soma quase duzentos milhões de habitantes (precisamente 190.732.694 habitantes). Entre estes a distribuição racial é de 96.795 .294 negros (7,6\% de pretos e 43,1\% de pardos); 91.051.646 de brancos (47,73\%); 2.084.288 asiáticos (1.1\%); e, 817.963 indígenas (o,4\%).

Os números demonstram que a maior parte da população passa a identificar-se como negra. O método utilizado para obtenção desse resultado foi a auto declaração, pois para caracterizar a população brasileira segundo recorte racial, a pergunta se refere à composição da população em termos de cor e raça.

Segundo Dionísio Baró et al (2009, p. 94), "há um quase-consenso no país segundo o qual o melhor modo de fazer a pergunta é a auto identificação como uma dentre as cinco categorias: preto, pardo, branco, indígena e amarelos além da opção não-declarado".

Constata-se que a utilização da auto identificação contribuiu para o aumento do percentual de negros. A esse fenômeno, Baró et al (2009, p. 94) atribuem como uma das explicações à hipótese que, "em razão do crescimento da consciência racial, as pessoas estejam mudando a forma como se declaram nas estatísticas oficiais".

Deve-se considerar as reações positivas da população negra aos investimentos institucionais, como, por exemplo, a auto declaração no censo. Mas, também, é necessário balizar as possibilidades de mudanças, coexistindo com fatores históricos, como a pobreza e exclusão.

Diantedessecenáriodereflexões ereposicionamentos, Mário Theodoro (2008, p. 174) argumenta que "pobreza se enfrenta com um conjunto amplo de cunho universalista, tendo como pano de fundo o crescimento econômico e a distribuição mais equânime da riqueza. Racismo, preconceito e discriminação devem ser enfrentados com 
outro conjunto de políticas e ações”. Esse conjunto são as ações afirmativas.

Importante se faz contextualizar a construção das ações afirmativas. Segundo Hédio Silva Jr. (2010, p. 25), deve-se considerar que, em uma sociedade como a brasileira, desfigurada por séculos de discriminação generalizada, não é suficiente que o Estado se abstenha de praticar a discriminação em suas leis. Incumbe ao Estado esforçar-se para favorecer a criação de condições que permitam a todos se beneficiarem da igualdade de oportunidades e eliminar qualquer fonte de discriminação direta ou indireta. A isso se dá o nome de ação afirmativa ou ação positiva, compreendida como comportamento ativo do Estado, em contraposição a atitude negativa, passiva, limitada à mera intenção de não discriminar.

No Brasil existe uma confusão entre o conceito de ações afirmativas e de cotas raciais ou sociais. As cotas são uma modalidade específica das ações afirmativas, o estabelecimento de um percentual numérico, tendo por base critérios de acesso e monitoramento do desenvolvimento e resultado. As ações afirmativas abarcam um conjunto de ações (as cotas e outras) que se combinam em objetivos e estratégias.

Nesse sentido, Márcia Lima (2010, p. 77) visualiza mudanças significativas provocadas pelo incessante debate na sociedade em geral, e no meio acadêmico em particular, considerando as reações favoráveis e contrárias às ações afirmativas. Mas em defesa da pertinência da adoção dessas políticas, argumenta que, "embora o debate tenha se concentrado fortemente no sistema de cotas para as universidades públicas, a atuação do governo envolve as ações afirmativas em outras áreas com características e escopos diferenciados".

Sales Augusto dos Santos (2008) alega que alguns cientistas sociais são contrários às cotas para negros por desconsiderarem a produção acadêmica sobre o tema, tratando-o como futurologia, afastando-se da construção de conhecimento fundamentado em pesquisas e no rigor acadêmico. Segundo o autor, as afirmações apresentam-se esvaziadas de conteúdo, como: "as cotas para negros nos vestibulares das universidades públicas vão racializar a sociedade brasileira', ou ainda, 'vai haver uma divisão racial do Brasil', ou 'divisões perigosas', entre outras insustentáveis previsões catastróficas” (Santos, 2008, p. 921).

O autor destaca que: a) mesmo os autores que são contra as cotas para negros nos vestibulares admitem que a sociedade brasileira discrimina racialmente os negros; b) o futuro passa a ser um dos argumentos desses autores contra o sistema de cotas, visto que eles descortinam, com a implementação das políticas de ação afirmativa para negros, cenários de conflito racial aberto. A partir dessas considerações é concluído por esses cientistas sociais que 
a implementação das cotas acirrará as tensões raciais existentes e provocará uma "cisão racial" no Brasil (Santos, 2008, p. 922).

Apesar dos profundos conflitos, de maneira positiva é possível enfatizar a educação étnico-racial como importante alavanca para a inserção social, esta contém em linhas gerais as perspectivas de recuperação do ensino público, democratização da educação em todos os níveis, destinação orçamentária específica; e, também, ensino da história da África, revisão do livro didático, garantia de pedagogia interétnica, inter-racial e não sexista, entre outros.

As proposições têm por base a realidade nacional no campo da educação, porém, no que diz respeito à situação educacional dos negros, Luiz Alberto Oliveira Gonçalves e Petronilha Beatriz Gonçalves e Silva (2000) argumentam que ocupam o lugar da exclusão e do abandono.

Detalhando um pouco mais o significado desse lugar ao qual o negro é impelido, Marcelo Paixão (2006, p. 8788) reflete que historicamente o sistema de ensino não reconheceu de maneira singular os alunos e alunas negros:

enfrentam uma série de problemas especificamente típicos desse grupo - a) a entrada precoce deste grupo no mercado de trabalho; b) a baixa qualidade do ensino público, onde se concentra a maioria dos estudantes afro descendentes, que não contribui para promover a construção do conhecimento; c) imposição de um conteúdo programático que não valoriza o universo dos afro descendentes e, portanto, não estimula a elevação de sua autoestima; d) a presença do racismo e do preconceito na sala de aula e no ambiente escolar, que reduz o estímulo à continuidade dos estudos; e) a falta relativa de bons exemplos no mercado de trabalho que possam sinalizar melhores perspectivas de retorno profissional financeiro mediante $o$ esforço em prol da continuidade dos estudos. (Paixão, 2006, p.87-88).

Como forma de reação a essa situação, nas proposições do Movimento Negro destaca-se o direito à educação. Gonçalves e Silva (2000) informam que são desenvolvidas estratégias educacionais, sobretudo a partir dos vários veículos que compuseram a imprensa negra, desde o século XX, e, no período contemporâneo após a criação do Movimento Negro Unificado (MNU), e, também, com a proliferação de inúmeras entidades negras em todo o país, a educação tem tomado maior vulto como ação política.

Quanto às políticas educacionais, Walter Roberto Silvério (2009, p. 34) considera as dimensões econômicas e 
simbólicas (redistribuição e reconhecimento). A dimensão econômica tendo por base as ações afirmativas (ou de cotas para negros e indígenas) "repõe para o debate público e acadêmico as implicações sociais da desconsideração da influência das características adscritas, tais como sexo e raça, na distribuição de oportunidades sociais e na manutenção e reprodução de padrões de desigualdade".

Já na dimensão simbólica, a ação afirmativa vincula-se ao reconhecimento, e, em geral, é motivada pelos movimentos sociais que têm por fundamento uma identidade cultural. "Tendo em conta que o étnico e o nacional são fenômenos da mesma natureza, ainda que de diferente magnitude, uma concepção ampliada e histórica da diversidade pode articular todas as diferenças incluídas as étnicas - e promovê-las com maior dignidade" (Silvério, 2009, p. 35).

Assim, a luta histórica pela educação étnico-racial com suas dimensões econômicas e simbólicas é ressaltada a partir dos anos 1980, com forte expressão na reivindicação pela democratização do ensino, o que pode ser visualizado em duas fases: a) a partir da denúncia do racismo e da ideologia escolar dominante, por meio da crítica ao livro didático, currículo, formação de professores etc.; e, b) pela substituição da denúncia pela ação concreta (Gonçalves e Silva, 2000, p. 55).

Luiz Alberto Gonçalves (2000, p. 337) informa que os interesses do Movimento Negro ao longo dos tempos apresentaram-se de maneira múltipla:

\begin{abstract}
ora vista como estratégia capaz de equiparar os negros aos brancos; ora como veículo de ascensão social e, por conseguinte de integração; ora como instrumento de conscientização por meio da qual os negros aprenderiam a história de seus ancestrais, os valores da cultura de seu povo, podendo a partir deles reivindicar direitos sociais e políticos, direito à diferença e respeito humano. (Gonçalves, 2000, p.337).
\end{abstract}

Diante desse histórico, o acúmulo das proposições do Movimento Negro é amplo e multifacetado. E, ao considerar o foco das ações afirmativas como base para a educação étnico-racial, serão apresentadas informações e reflexões sobre quatro questões:

- a implementação da Lei 10.639/03 (ensino da história e cultura afro-brasileira no ensino público e privado);

- o Programa Universidade para Todos - PROUNI (Lei 11.096/05 que concede bolsas a alunos pobres, indígenas e negros); 
8 A Lei 10.639 é de autoria da deputada Ester Grossi e do deputado Ben-Hur Ferreira, ambos do Partido dos Trabalhadores. Foi apresentada na Câmara dos Deputados como Projeto de Lei ${ }^{\circ}{ }^{259}$, em 11 de março de 1999, aprovado e remetido ao Senado no dia 05 de abril de 2002. O sancionamento pelo presidente Luiz Inácio Lula da Silva se deu em 09/01/2003, um de seus primeiros atos depois da posse.

9 Após a aprovação da Lei 10.639, um passo importante foi a garantia da representação do Movimento Negro, nos anos 2002 a 2004, pela conselheira Dra. Petronilha Beatriz Gonçalves e Silva do Conselho de Educação junto à Câmara de Educação Superior, sendo responsável pela elaboração do Parecer CNE/CP 3/2004 que regulamenta as Diretrizes Curriculares Nacionais para a Educação das Relações Étnico-Raciais e para o Ensino da História e Cultura Afro-Brasileira e Africana instituído pela Resolução CNE/CP 1/2004.
- as Cotas nas Universidades Públicas (Lei 12.711/12 que promove o acesso a alunos pobres, indígenas e negros); e,

- a criação em 20 de julho de 2010 da Universidade de Integração Internacional da Lusofonia Afro-Brasileira (UNILAB) uma autarquia federal de ensino superior.

A Lei 10.639/03 ${ }^{8}$ aprovada pelo governo federal em 09/01/2003 alterou a Lei de Diretrizes e Bases da Educação Nacional (LDB) $\mathrm{n}^{0}$ 9.394/96, e, indicou a inclusão no currículo dos níveis fundamental e médio da rede pública e privada o ensino de História e Cultura Afro-Brasileira. Em complemento, em 11/o3/2008 foi criada a Lei 11.645/o8, tornando também obrigatório o ensino da história e cultura dos povos indígenas. O Conselho Nacional de Educação elaborou um parecer com as Diretrizes Curriculares Nacionais para a Educação das Relações Étnico-Raciais e para o Ensino da História e Cultura Afro-Brasileiras e Africanas (Parecer CNE/CP n. 3 de 10/03/2004) e a Resolução CNE/CP n. 1 de 17/o6/2004), regulamentando, portanto, a alteração da $\mathrm{LDB}^{9}$.

Segundo Ricardo Henriques e Eliane Cavalleiro (2005, p. 217), todo esse processo constitui uma linha divisória na política educacional brasileira: "Pela primeira vez, há o tratamento explícito da dinâmica das relações raciais nos sistemas de ensino, bem como sobre a inserção no currículo escolar da história e cultura afro-brasileira e africana".

Constata-se que o caminho de construção da Lei 10.639 é muito antigo, antecedendo a sua aprovação pelo Governo Lula. Nesse sentido, Gomes (2009, p. 41) argumenta que a Lei 10.639 e suas diretrizes curriculares "são fruto de um processo de lutas sociais e não da dádiva de um Estado. Uma política pública voltada para a diversidade étnico-racial precisa reconhecer e dialogar com as lutas históricas da população negra”.

Há o reconhecimento de que a Lei 10.639 foi um passo importante para a democratização do ensino, o que necessita de grande investimento. Assim, como forma de reforçar sua implementação, o governo federal criou, em 2009, o Plano Nacional de Implementação das Diretrizes Curriculares Nacionais da Educação das relações ÉtnicoRaciais e para o Ensino da História e Cultura AfroBrasileira e Africana. Nesse plano são destacados como eixos: fortalecimento do marco legal; formação inicial e continuada; materiais didáticos e paradidáticos; gestão democrática e mecanismos de participação social; avaliação e monitoramento; e condições institucionais.

Reforça-se a necessidade do desenvolvimento da transparência da ação governamental e do controle social a ser exercido por organizações e movimentos da sociedade civil. O plano possibilita, portanto, o estabelecimento de metas que garantam o cumprimento que obriga o ensino 
10A proposta apresentada foi elaborada pelo Grupo de Trabalho Interministerial (GTI) coordenado pelo Ministério da Educação e pela SEPPIR, em diálogo com o Movimento Negro. Para a síntese que posteriormente foi incluída no Projeto de Lei 73/99, foram analisados os projetos que tramitavam no legislativo e também as proposições da sociedade civil. da história da África e de outras legislações comprometidas com a promoção da igualdade racial (Brasil, 2009).

Outro importante instrumento é o Programa Universidade para Todos - PROUNI (Lei 11.096/05), iniciativa destinada a ampliar o ingresso de estudantes de baixa renda no ensino superior privado, propiciando o acesso e permanência em instituições privadas de ensino, que vem atuando de forma efetiva na inserção de estudantes negros, pobres e indígenas. Segundo o Instituto de Pesquisa Econômica Aplicada - IPEA, em Políticas de Acompanhamento e Análise (n. 15, 2008, p. 228), o ProUni "tem permitido uma inserção massiva dos estudantes negros no ensino privado brasileiro".

$\mathrm{Na}$ área do ensino público, a inserção nas universidades públicas por meio das cotas tem sido parte das formulações e negociações do Movimento Negro e junto ao governo federal e governos locais. A Presidência da República encaminhou, em 13 de maio de 2004, proposta ao Legislativo ${ }^{10}$, que foi incluída em Projeto de Lei que tramitava na Câmara Federal, desde 1999, sendo aprovado e sancionado pela presidenta Dilma Rousseff, em 2012.

Assim, por meio da Lei 12.711, passa a ser assegurada a reserva de $50 \%$ das vagas das universidades federais e estaduais e das instituições de ensino técnico federais para estudantes oriundos de escolas públicas, garantindo a distribuição entre negros, pardos e indígenas, proporcional à composição da população em cada Estado, tendo como base as estatísticas mais recentes do Instituto Brasileiro de Geografia e Estatística (IBGE). Esta lei será aplicada progressivamente por um período de 10 anos, sendo prevista avaliação dos resultados e perspectiva de redefinição.

Entre a elaboração e o sancionamento da Lei, boa parte das universidades públicas aplicaram as cotas. Como exemplos, destacaram-se a Universidade de Brasília (UnB) como a primeira federal a aprovar o sistema de cotas em 2004, e no mesmo período as experiências da Universidade Estadual do Rio de Janeiro (UERJ) e da Universidade Estadual da Bahia (UNEB).

Essas experiências fomentaram intenso processo de debates e diálogos entre os professores, os alunos, o movimento social e o governo. Segundo o IPEA (2008, p. 231):

A inserção da juventude negra nas instituições públicas representa mais que um debate qualitativo. Significa também a inserção dessa população nos principais centros de pesquisa e de debate sobre os problemas nacionais. Ao mesmo tempo, a presença desse grupo nas instituições tem permitido avanços na realização do princípio de democratização do acesso, com consequências na 'desracialização' da elite estudantil brasileira. Propicia também, dada a nova composição do corpo 
discente, um ambiente novo nos debates sobre o enfrentamento dos temas desafiadores da transformação do país, no sentido da promoção de maior equidade racial e social.

A UNILAB estrutura-se a partir de dois Estados: Ceará (nos municípios de Redenção e Acarape) e Bahia (São Francisco do Conde), respectivamente os campi de Liberdade, Palmares e Auroras e campus dos Malês. Esta universidade desenvolve-se a partir da perspectiva de interiorização e internacionalização do ensino superior, considerando a efetivação do encontro da nacionalidade brasileira com sua história e cultura, reafirmando em suas diretrizes a missão de produção e disseminação do conhecimento em atendimento à demanda de formação e de pesquisa de países de expressão em língua portuguesa, em um ambiente de respeito às distintas identidades, ao pluriculturalismo e à cooperação solidária.

Esta universidade prima pela promoção da cooperação com países, territórios e comunidades em diferentes partes do mundo, que adotam como língua oficial ou se expressam em língua portuguesa, sendo estes: Angola, Cabo Verde, Guiné Bissau, Moçambique, São Tomé e Príncipe (no Continente Africano); Timor Leste e Macau (na Ásia); e, Portugal (na Europa).

Tendo em sua base alunos brasileiros e dos países mencionados, a UNILAB, na atualidade, tem como prioridades as áreas: Agricultura, Energia e Tecnologias de Desenvolvimento Sustentável, Formação Docente, Gestão Pública, e Saúde Coletiva.

De maneira geral, verifica-se que as quatro medidas utilizadas como exemplos trazem inovações importantes diante da reflexão e prática de democratização do ensino. Configuram-se como produtos de debates propositivos e controversos na sociedade, sobretudo, a partir das ações governamentais incrementadas nas últimas décadas.

Deve-se considerar que essas construções interferiram no Plano de Desenvolvimento da Educação (PDE), que aponta para questões universais e específicas no sistema de ensino, como as próprias ações afirmativas.

Portanto, as medidas, substanciadas por leis ou por reorganizações estruturais, são inovações no sistema de ensino; por isso, mesmo já em exercício, provocam debates e mobilizações no interior da administração pública e também na sociedade.

\section{BREVES CONSIDERAÇÕES PARA O PRESENTE E O FUTURO}

O caminho para mudanças é complexo, mas a realidade não é imutável. O fortalecimento da identidade 
negra e da consciência racial tem sido elemento importante nessa construção (Ribeiro, 2014).

Do ponto de vista histórico, tendo em vista o conjunto das questões educacionais (étnico-raciais), verifica-se que em se tratando da ação do Estado a marca foi exclusão e abandono. Por outro lado, é reafirmada a importância de uma luta continuada dos negros para garantia de cidadania e direitos, e também, avanços no desenvolvimento dessas políticas, nas últimas décadas.

Desde a construção de estruturas até as diretrizes, instrumentos e programas de ações afirmativas em âmbito local e nacional, verifica-se que os caminhos foram diversos; no entanto, exigiu uma grande dose de determinação política acompanhada de definições de leis e instrumentos que institucionalizam as políticas de igualdade racial.

Fica mais do que explícita a complementação existente entre as políticas universais e as ações afirmativas em várias áreas da administração pública: saúde, segurança alimentar, justiça, entre outras. Nesse artigo foi destacada a educação étnico-racial, como uma importante alavanca visando a efetivação da democracia.

Diante de toda a reflexão e experiências em curso, destaca-se uma frase síntese para demarcar os desafios do momento atual: no século XXI o Estado brasileiro deve acelerar o processo de inclusão, a partir das políticas raciais, como foco da justiça social.

\section{REFERÊNCIAS}

ALVAREZ, Sonia. Construindo uma política feminista translocal da tradução. Revista Estudos Feministas, Florianópolis, Universidade Federal de Santa Catarina, Centro de Filosofia e Ciências Humanas, Centro de Comunicação e Expressão,17, 3:312, set./dez. 2009.

AZEREDO, Sandra. Teorizando sobre gênero e relações raciais. Revista de Estudos Feministas, Rio de Janeiro, $\mathrm{n}^{0}$ especial, p. 203-16, 1994.

BAIRROS, Luiza. Nossos feminismos revisitados. Revista de Estudos Feministas, Rio de Janeiro, n. 2, p. 458-63, 1995.

BARÓ, Dionísio et al. Desigualdade racial e construção institucional: a consolidação da temática racial no governo federal. In: JACCOUD, Luciana (Org.). A Construção de uma política de promoção da igualdade racial - uma análise dos últimos 20 anos. Brasília: IPEA, 2009.

BASTIDE, Roger; FERNANDES, Florestan. Brancos e negros em São Paulo: ensaio sociológico sobre aspectos da formação, manifestações atuais e efeitos do preconceito de cor na sociedade paulistana. 4. ed. São Paulo: Global, 2008. 
BENTO, Maria Aparecida Silva. A Mulher Negra no mercado de trabalho. Revista Estudos Feministas, Rio de Janeiro, Universidade Federal do Rio de Janeiro e Instituto de Filosofia e Ciências Sociais, v. 3, n. 2, p. 47995, 1995 .

BRASIL. Ministério da Educação. Diretrizes Curriculares Nacionais para a Educação das Relações Étnico-Raciais e para o Ensino de História e Cultura Afro-Brasileira e Africana. Brasília, 2003. $35 \mathrm{p}$.

BRASIL. Secretaria de Promoção da Igualdade Racial (Seppir). Plano Nacional de Promoção da Igualdade Racial - PLANAPIR. Brasília, 2009.

CALDEWELL, Kia Lilly.Negras in Brazil: re-envisioning black women, citizenship, and politics of identity. United States of America: British Library, 2007.

CARNEIRO, Sueli. Enegrecer o feminismo: a situação da mulher negra na América Latina a partir de uma perspectiva de gênero. In: ASHOKA EMPREENDIMENTOS SOCIAIS; TAKANO CIDADANIA (Org.). Racismos contemporâneos. Rio de Janeiro: Takano Editora, 2003. p. 49-58.

CRENSHAW, Kimberle. Documento para Encontro de Especialistas em Aspectos da Discriminação Racial Relativos ao Gênero. In: Dossiê III Conferência Mundial contra o Racismo. Revista de Estudos Feministas, Florianópolis, Universidade Federal de Santa Catarina, v. 10, n. 1, p.171-88, 2002.

DATAFOLHA. I Pesquisa sobre preconceito de cor. Especial. Folha de São Paulo, São Paulo, 1995.

DOMINGUES, Petrônio. Movimento Negro Brasileiro: Alguns apontamentos históricos. Revista Tempo Histórico (On-line), Rio de Janeiro, Departamento da Universidade Federal Fluminense, UFF, v. 2, n. 23, 2007. Disponível em: <http://aldeiagriot.blogspot.com. br/2008/11/artigo-movimento-negro-brasileiro.html >. Acesso em: out. 2012.

GOMES, Nilma Lino. Limites e possibilidades da implementação da Lei 10.639/o3 no contexto das políticas públicas em educação. In: PAULA, Marilene; HERINGER, Rosana. Caminhos convergentes: Estado e Sociedade na superação das desigualdades raciais no Brasil. Rio de Janeiro: Fundação Heinrich Boll, Action Aid, 2009. p. 39-74.

GONÇALVES, Luiz Alberto Oliveira. Negros e educação no Brasil. In: LOPES, E. M. et al. 500 anos de Educação no Brasil. Belo Horizonte: Autêntica, 2000. p. 325-46.

GONÇALVES, Luiz Alberto Oliveira; SILVA, Petronilha Beatriz Gonçalves. Movimento Negro e Educação. Revista Brasileira de Educação, n. 15, set./out./nov./dez., 2000. 
GONZALEZ, Lélia; HASENBALG, Carlos. Lugar de negro. Rio de Janeiro: Marco Zero, 1982.

GORENDER, Jacob. O escravismo Colonial. São Paulo: Editora Perseu Abramo, 2010.

GUIMARÃES, Antônio Sergio. Classes, raças e democracia. 34. ed. São Paulo: Fundação de Apoio à Universidade de São Paulo, 2002.

HENRIQUES, Ricardo; CAVALLEIRO, Eliane. Educação e Políticas Públicas Afirmativas: elementos da agenda do Ministério da Educação. In: SANTOS, Sales Augusto (Org.). Ações afirmativas e combate ao racismo nas Américas. Brasília: Ministério da Educação, Secretaria de Educação Continuada, Alfabetização e Diversidade, 2005. p. 211-27.

INSTITUTO DE PESQUISA ECONÔMICA APLICADA IPEA. Políticas de Acompanhamento e Análise, n. 15, 2008, p. 228. Disponível em: http://www.ipea.gov.br/portal/ images/stories/PDFs/politicas_sociais/16_completo15. pdf

LIMA, Marcia. Desigualdades Raciais e Políticas Públicas - As Ações Afirmativas no Governo Lula. Revista Novos Estudos Cebrap, São Paulo, n. 87, jul. 2010.

MAESTRI, Mário. O Escravismo no Brasil. São Paulo: Atual, 1994.

MARCHA Zumbi contra o Racismo, pela Cidadania e a Vida. Por uma política nacional de combate ao racismo e a desigualdade racial. Brasília: Cultura Gráfica e Editora Ltda., 1996.

MUNANGA, Kabengele; GOMES, Nilma Lino. Para entender o negro no Brasil de hoje: História, realidades, problemas e caminhos. São Paulo: Global e Ação Educativa Assessoria, Pesquisa e Informação, 2004.

NASCIMENTO, Abdias. Quilombo. Vida, problema e aspirações do negro. 1. ed. Rio de Janeiro: Editora 34, 2003.

NASCIMENTO, Abdias. O Negro revoltado. 2. ed. Rio de Janeiro: Nova Fronteira, 1982.

NASCIMENTO, Abdias. O quilombismo. Petrópolis: Vozes. 1980. (Documento n. 7).

OLIVEIRA, Fátima; IRACI, Nilza; RIBEIRO, Matilde. A mulher negra na década: a busca de autonomia. São Paulo: GELEDÉS, 1995.

PAIXÃO, Marcelo. Manifesto antirracista: idéias em prol de uma utopia chamada Brasil. Rio de Janeiro: DP\&A; LPP/UERJ, 2006.

PARTIDO DOS TRABALHADORES (PT). Programa de

Campanha. Política de Igualdade Racial, 2006. 
PARTIDO DOS TRABALHADORES (PT). Programa de Campanha. Programa Brasil sem Racismo, 2002.

REIS, João José. Presença Negra, conflitos e encontros. Brasil 500 Anos. Rio de Janeiro: Instituto Brasileiro de Geografia e Estatística, 2000.

RIBEIRO, Matilde.Políticas de Promoção da Igualdade Racial no Brasil (1986-2010). Rio de Janeiro: Editora Garamond Universitária, 2014.

RIBEIRO, Matilde. O feminismo em novas rotas e visões. Revista Estudos Feministas, Florianópolis, Universidade Federal de Santa Catarina, Centro de Filosofia e Ciências Humanas e Centro de Comunicação e Expressão, v. 14, n. 3, p. 801-11, 2006.

RIBEIRO, Matilde.Mulheres negras brasileiras, de Bertioga a Beijing. Revista de Estudos Feministas, Rio de Janeiro, v. 3, n. 2, 1995.

SANTOS, Hélio. A busca de um caminho para o Brasil. A trilha do círculo vicioso. São Paulo: Editora SENAC, 2001.

SANTOS, Sales Augusto et al. Ações Afirmativas: Polêmicas e Possibilidades sobre Igualdade Racial e Papel do Estado. In: RIBEIRO, Matilde; PIOVESAN, Flávia (Coorg.). Dossiê - "120 anos da Abolição da Escravidão no Brasil: Um processo ainda inacabado". Estudos Feministas, Florianópolis, Universidade e Santa Catarina, v.16, n. 3, p. 913-28, 2008.

SILVA JR., Hédio. Conceitos e Demarcações Históricas. In: SILVA, Hédio; BENTO, Maria Aparecida; SILVA, Mario Rogério. Políticas Públicas de Promoção de Igualdade Racial. São Paulo, SP: CEERT, 2010.

SILVERIO, Valter Roberto. Evolução e contexto atual das políticas públicas no Brasil: educação, desigualdade e reconhecimento. In: PAULA, M.; HERINGER, Rosana. Caminhos convergentes: Estado e Sociedade na superação das desigualdades raciais no Brasil. Rio de Janeiro: Fundação Heinrich Boll, ActionAid, 2009. p. 13-38.

SOARES, Vera. O feminismo e o Machismo na Percepção das Mulheres Brasileiras. In: VENTURI, Gustavo; RECAMAN, Marisol; OLIVEIRA, Suely. A mulher brasileira nos espaços público e privado. São Paulo: Editora Fundação Perseu Abramo, 2004. p.162-82.

THEODORO, Mário (Org.). A formação do mercado de trabalho e a questão racial no Brasil. As políticas públicas e desigualdade racial no Brasil: 120 anos após a abolição. Brasília: Instituto de Pesquisa Econômica Aplicada (IPEA), 2008. 